\title{
Changes of serum 25(OH) D3 and IGF-1 levels in patients with thyroid nodules
}

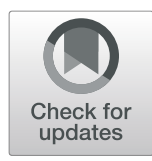

Xueqin Du', Yi Liu², Chunhui Zhao ${ }^{3}$, Jingzhou Fang ${ }^{2}$, Xiangna Wang ${ }^{2}$ and Limin Wei ${ }^{4^{*}}$

\begin{abstract}
Background: The present study aimed to study the relationship between serum 25 hydroxyvitamin D3(25(OH)D3) and insulin-like growth factor-1 (IGF-1) and thyroid nodules.

Methods: Two hundred eighty-nine cases with thyroid nodules and 109 health subjects (control group) who admitted to the Hebei General Hospital during June 2016 to December 2016 were included in the study. Basic clinical information (age, sex, thyroid function, liver and kidney function, hypertension history, etc.) of patients were collected. Serum 25(OH) D3 and Serum IGF-1 were detected by electrochemiluminescence and radioimmunoassay methods, respectively. The relationship between the above-mentioned factors and thyroid nodules was statistically analyzed.
\end{abstract}

Results: Serum 25(OH)D3, IGF-1, fasting blood glucose (FBG), total cholesterol (TC), waist circumference (WC), total triiodothyronine (TT3), total thyroxine (TT4), hypertension history, and drinking history were significantly different between the nodules group and the control group $(P<0.05)$. Logistic regression analysis showed that there was a negative correlation between thyroid nodules and levels of $25(\mathrm{OH}) \mathrm{D} 3, \mathrm{IGF}-1, \pi \mathrm{T}$, as well as a positive correlation with FBG, TC, $\Pi 4$, and hypertension. There was a positive correlation between IGF-1 and serum 25(OH)D3 in thyroid nodules $(P<0.05)$. After correcting the aforementioned factors, high-level of serum 25(OH) D3 was significantly correlated with the decreased incidence of thyroid nodules.

Conclusions: The incidence of thyroid nodules is relatively lower in a high-level of serum 25(OH)D3, and serum 25(OH) D3 may be a direct protective factor for thyroid nodules. Serum IGF-1 can be one of the indirect protective factors for thyroid nodules as well.

Keywords: Thyroid nodules, 25(oh)D3, Insulin-like growth factor-1, Deficiency of vitamin D, Correlation analysis

\section{Background}

Thyroid nodules is an independent lesion in the thyroid gland, and it is one of the common diseases on the endocrine system. With the broad application of high frequency ultrasound scanning, the detection rate of thyroid nodules in healthy population has reached as high as $50-60 \%$ [1], and that is more common in female and elderly people as well. With the popularization of health examination and the appearance of thyroid color Doppler as a general examination item, the detection rate of several asymptomatic thyroid nodules is increasing, and individuals pay further attention to it. At present, the pathogenesis of thyroid nodules is not fully clear.

\footnotetext{
*Correspondence: 15133130672@163.com

${ }^{4}$ Department of Endocrinology, Hebei General Hospital, Shijiazhuang 050051, Hebei, China

Full list of author information is available at the end of the article
}

The lack of vitamin D3 is closely associated with the development of a variety of diseases such as, cardiovascular disease and malignant tumor. However, the relationship between the changes of serum vitamin D3 levels and the thyroid nodules is not still clear. Roskies et al. [2] found that the lack of serum 25(OH)D3 may be associated with the occurrence of thyroid cancer. IGF-1 probably plays an important role in the genesis and development of certain solid cold thyroid nodules, including papillary thyroid carcinomas, nodular goiters, and follicular adenomas [3]. High 25(OH)D3 level may be a factor in reducing cell proliferation and inducing apoptosis through complementary pathways or mechanisms.

Based on the above-mentioned researches, the purpose of this study is to further clarify the changes and interactions of serum 25(OH)D3 and IGF-1 levels in patients 
with thyroid nodules. The results provide further theoretical basis for the study of the mechanism of thyroid nodule development.

\section{Methods \\ Subjects}

Here, 410 health examination subjects were collected in Hebei General Hospital (China) during June 2016 to December 2016 with ultrasound examination. Among them, 300 cases found with thyroid nodules, while 110 cases did not have thyroid nodules. Exclusion criteria: thyroid nodules demonstrated malignant tendency of thyroid ultrasound, abnormality of thyroid function, thyroid related diseases, liver and kidney diseases, diabetes, malignancies, acromegaly, and subjects with the history of acute disease. The final subjects included 289 cases with thyroid nodules (nodule group) and 109 cases as normal subjects (control group). All subjects did not take therapies (LT4, cholecalciferol, etc.) that could affect the parameters considered.

\section{Methods \\ Collection of general data}

All participants were asked to fill in questionnaires designed by professionals (The questionnaire see in Additional file 1). General information covered sex, age, hypertension history, smoking, and drinking. All the subjects were tested based on the body parameters by the same group of operators, including height, weight, waist circumference, blood pressure, and body mass index (BMI).

\section{Ultrasound examination}

Ultrasound examination of thyroid nodules was using PHILIPS EPIQ7 color Doppler ultrasound system, L125 probe, frequency $7 \sim 12 \mathrm{MHz}$. The size of thyroid nodules was recorded, the ultrasonic data of thyroid nodules were quantified, and the cross-sectional area of thyroid nodules was calculated as well.

\section{Detection of metabolic parameters}

Biochemical tests were performed on fasting blood for $8-10 \mathrm{~h}$. The main factors including fasting blood glucose (FBG), total cholesterol (TC), triglyceride (TG), high density lipoprotein cholesterol (HDL-C), low density lipoprotein cholesterol (LDL-C) were analyzed by an automatic biochemical analyzer, and serum 25(OH)D3, fasting insulin (FINS) and thyroid function were measured by electrochemiluminescence, and serum IGF-1 was determined by radioimmunoassay.

\section{Statistical analysis}

Data obtained from the study were analyzed using SPSS 19.0 software (SPSS Inc., IL, USA). The normal distribution of measurement data was expressed by mean \pm standard deviation $(\bar{x} \pm \mathrm{s})$, and non-normal state of measurement data is expressed by median (four quantiles). Two samples were normal and the variance was homogeneous compared with $t$-test, otherwise, a non-parametric test needed to be applied. Comparing the differences between two or more overall rates or the correlation between categorical variables were performed by $\chi^{2}$ test. A linear correlation analysis between two variables was carried out using Spearman's correlation test. Two correlation analyses between categorical variables and some effective factors were undertaken using Logistic Regression Analysis. (LRA) P-value $<0.05$ was statistically considered significant.

\section{Results}

Comparing the general data between the nodular group and the control group

The gender, age, 25(OH)D3, IGF-1, FBG, blood lipid, thyroid function, liver function, and other factors in the nodular group and the control group were compared. The results showed that the serum $25(\mathrm{OH}) \mathrm{D} 3$ level in the nodular group was lower than that in the control group $(9.86 \pm 6.66$ vs. $12.74 \pm 7.13 \mathrm{ng} / \mathrm{L})(P<0.001)$; the serum IGF-1 level in the nodular group was lower than that in the control group $(111.10(81.53,165.44)$ vs. $192.65(96.38,313.49) \mathrm{ng} / \mathrm{L})$, and the differences were statistically significant $(P<0.001)$ (Table 1$)$. The FBG, TC, WC, TT3, TT4, and hypertension and drinking histories were different between the two groups $(P<0.05)$.

\section{The correlation between the single factors and the thyroid nodules}

Thyroid nodule was analyzed by LRA to reveal the effects of the single factors on the thyroid nodules, including sex, age, 25(OH)D3, IGF-1, FBG, blood lipid, WC, uric acid, thyroid function, liver function, BMI, HbA1c, HOMA-IR, hypertension, smoking history, and drinking history. The variables included FBG, TC, TT3, TT4, hypertension, 25(OH)D3, and IGF-1. The $\chi^{2}$ value of LRA is $148.037(P<0.05)$, so the LRA has statistical significance. Therefore, 25(OH)D3, IGF-1 and TT3 were negatively correlated with thyroid nodules, while FBG, TC, TT4, and hypertension were positively correlated with thyroid nodules (Table 2).

The correlation of serum 25(OH)D3 and IGF-1 with each factor The correlation of serum 25(OH)D3 with age, IGF-1, FBG, blood lipid, FINS, thyroid function, liver function, and cross sectional area of thyroid nodules was analyzed by Spearman's correlation analysis. The results showed that serum 25(OH)D3 was positively correlated with IGF-1(Table 3) $(r=0.123, P=0.037)$, while there was no significant correlation with aforementioned factors.

The results of correlation between serum IGF-1 and aforementioned factors showed that the serum IGF-1 
Table 1 Difference analysis of basic clinical information between the nodule group and control group

\begin{tabular}{|c|c|c|c|}
\hline & Thyroid nodules & Control & $P$ value \\
\hline$n$ & 289 & 109 & \\
\hline Age(year) & $46(40,53)$ & $45(40,49.5)$ & 0.351 \\
\hline Sex & & & 0.498 \\
\hline Male & 158(54.67) & $64(58.72)$ & \\
\hline Female & 131(45.33) & 45(41.28) & \\
\hline $\mathrm{ALT}(\mathrm{U} / \mathrm{L})$ & $25.31 \pm 19.57$ & $26.38 \pm 17.20$ & 0.621 \\
\hline AST(U/L) & $21.03 \pm 9.03$ & $20.83 \pm 7.10$ & 0.841 \\
\hline$r-G T(U / L)$ & $34.73 \pm 36.59$ & $32.46 \pm 29.49$ & 0.562 \\
\hline Uric(umol/L) & $314.39 \pm 84.70$ & $318.06 \pm 78.24$ & 0.694 \\
\hline $\mathrm{FBG}(\mathrm{mmol} / \mathrm{L})$ & $5.42(5.07,5.94)$ & $5.20(4.92,5.43)$ & $<0.001$ \\
\hline $\mathrm{TC}(\mathrm{mmol} / \mathrm{L})$ & $5.17 \pm 0.93$ & $4.62 \pm 0.86$ & $<0.001$ \\
\hline $\mathrm{TG}(\mathrm{mmol} / \mathrm{L})$ & $1.25(0.84,1.99)$ & $1.13(0.81,1.69)$ & 0.195 \\
\hline $\mathrm{HDL}-\mathrm{C}(\mathrm{mmol} / \mathrm{L})$ & $1.29 \pm 0.33$ & $1.30 \pm 0.29$ & 0.764 \\
\hline LDL-C(mmol/L) & $2.58 \pm 0.65$ & $2.54 \pm 0.66$ & 0.628 \\
\hline $\mathrm{BMI}\left(\mathrm{kg} / \mathrm{m}^{2}\right)$ & $25.63 \pm 3.37$ & $25.04 \pm 3.70$ & 0.129 \\
\hline WC(cm) & $88.19 \pm 10.44$ & $85.60 \pm 11.41$ & 0.032 \\
\hline Smoking & & & 0.239 \\
\hline Never & $197(68.17)$ & $83(76.15)$ & \\
\hline Former & $16(5.54)$ & $3(2.75)$ & \\
\hline Current & $76(26.29)$ & $23(21.10)$ & \\
\hline Drinking & & & 0.021 \\
\hline Never & $151(52.25)$ & 48(44.034) & \\
\hline Former & $7(2.42)$ & $1(0.92)$ & \\
\hline Sometimes & $63(21.80)$ & $40(36.70)$ & \\
\hline Often & $68(23.53)$ & $20(18.34)$ & \\
\hline ПT3(pmol/L) & $1.96 \pm 0.35$ & $2.09 \pm 0.27$ & $<0.001$ \\
\hline TT4(pmol/L) & $111.62 \pm 20.16$ & $98.42 \pm 15.19$ & $<0.001$ \\
\hline TSH(ulU/ml) & $1.89 \pm 1.72$ & $2.00 \pm 0.98$ & 0.366 \\
\hline TPOAb(IU/ml) & $10.54(6.82,15.89)$ & $11.74(8.23,16.85)$ & 0.139 \\
\hline FINS(uU/ml) & $9.93 \pm 7.61$ & $9.95 \pm 5.26$ & 0.971 \\
\hline 25(OH)D3(ng/L) & $9.86 \pm 6.66$ & $12.74 \pm 7.13$ & $<0.001$ \\
\hline |GF-1 (ng/ml) & $111.10(81.53,165.44)$ & $192.65(96.38,313.49)$ & $<0.001$ \\
\hline HOMA-IR & $1.96(1.25,3.19)$ & $2.20(1.52,2.82)$ & 0.929 \\
\hline Hypertention & $55(19.03)$ & $5(4.59)$ & $<0.001$ \\
\hline
\end{tabular}

was negatively correlated with FBG (Table 4) $(r=-$ $0.207, P<0.001)$, and was positively correlated with 25(OH)D3 ( $r=0.123, P=0.037)$, while no significant correlation was found with other factors.

\section{Correlation between 25(OH)D3 level and incidence of thyroid nodules}

According to the quantile of serum 25(OH)D3, all the subjects were divided into four groups: Q1: $<5.19 \mathrm{ng} / \mathrm{L}$ $(n=99), \mathrm{Q} 2: 5.20-9.59 \mathrm{ng} / \mathrm{L}(n=100), \mathrm{Q} 3: 9.6-14.01 \mathrm{ng} /$
Table 2 The correlation results between the single factors and thyroid nodules

\begin{tabular}{llllll}
\hline $\begin{array}{l}\text { Dependent } \\
\text { variables }\end{array}$ & $\begin{array}{l}\text { Independent } \\
\text { variables }\end{array}$ & $\mathrm{B}$ & $\mathrm{OR}$ & $95 \% \mathrm{Cl}$ & $P$ value \\
\hline Thyroid nodules & FBG & 0.610 & 1.840 & $1.123-3.015$ & 0.016 \\
& TC & 0.418 & 1.518 & $1.086-2.127$ & 0.015 \\
& TT3 & -3.977 & 0.019 & $0.005-0.066$ & $<0.001$ \\
& T4 & 0.079 & 1.082 & $1.058-1.106$ & $<0.001$ \\
& Hypertention & 0.661 & 3.752 & $1.220-11.534$ & 0.021 \\
& 25(OH)D3 & -0.047 & 0.954 & $0.917-0.991$ & 0.016 \\
& IGF-1 & -0.002 & 0.998 & $0.996-1.000$ & 0.013 \\
\hline
\end{tabular}

$\mathrm{L}(n=101)$, and Q4: $\geq 14.02 \mathrm{ng} / \mathrm{L}(n=98)$, and the incidence of thyroid nodules for each group was 84.8, 75, 72.3 , and $58.2 \%$, respectively. The results showed that the incidence of thyroid nodules in group Q3 and group Q4 was lower than that in group Q1, and the difference was statistically significant $(P=0.030)$. The incidence of thyroid nodules in group Q2 was lower than that in group Q1, however, the difference was not statistically significant $(P=0.083)$ (Fig. 1$)$.

As LRA showed that IGF-1, TT3, FBG, TC, TT4, and hypertension were also associated with thyroid nodules, correction of the above-mentioned factors (i.e., the correction of different confounding factors through Model 1 (unadjusted), Model 2 (adjusted for FBG, TC, TT3, TT4, and hypertension factors), and Model 3 (further adjusted for IGF-1)) was used to further assess the correlation between the $25(\mathrm{OH}) \mathrm{D} 3$ level and the incidence of thyroid nodules (Table 5).

In Model 1, as a reference for Q1 group, compared with Q3 group, the risk of thyroid nodules decreased $(\mathrm{OR}=0.682$, 95\% CI: 0.481-0.969); after Model 2 corrected FBG, TC, TT3, TT4, and hypertension, the risk of thyroid nodules in Q3 group was still lower than that in

Table 3 The correlation analysis results of serum 25(OH)D3 and various factors

\begin{tabular}{|c|c|c|c|c|c|}
\hline & $r$ & $P$ value & & $r$ & $P$ value \\
\hline Age(year) & 0.030 & 0.087 & $\mathrm{BMI}\left(\mathrm{kg} / \mathrm{m}^{2}\right)$ & 0.022 & 0.390 \\
\hline $\mathrm{ALT}(\mathrm{U} / \mathrm{L})$ & -0.042 & 0.477 & $W C(\mathrm{~cm})$ & 0.024 & 0.360 \\
\hline AST(U/L) & -0.069 & 0.240 & $\Pi \pi 3(\mathrm{pmol} / \mathrm{L})$ & -0.036 & 0.539 \\
\hline r-GT(U/L) & 0.034 & 0.570 & TT4(pmol/L) & -0.036 & 0.545 \\
\hline Uric(umol/L) & -0.002 & 0.974 & TSH(ulU/ml) & -0.072 & 0.219 \\
\hline $\mathrm{FBG}(\mathrm{mmol} / \mathrm{L})$ & -0.360 & 0.540 & TPOAb(IU/ml) & -0.002 & 0.968 \\
\hline $\mathrm{TC}(\mathrm{mmol} / \mathrm{L})$ & 0.015 & 0.804 & FINS(uU/ml) & -0.024 & 0.683 \\
\hline $\mathrm{TG}(\mathrm{mmol} / \mathrm{L})$ & 0.033 & 0.572 & IGF-1(ng/ml) & 0.123 & 0.037 \\
\hline $\mathrm{HDL}-\mathrm{C}(\mathrm{mmol} / \mathrm{L})$ & 0.043 & 0.466 & HOMA-IR & -0.020 & 0.732 \\
\hline LDL-C(mmol/L) & 0.071 & 0.228 & $\begin{array}{l}\text { Thyroid nodules } \\
\text { cross-sectional } \\
\text { area }\left(\mathrm{mm}^{2}\right)\end{array}$ & 0.080 & 0.176 \\
\hline
\end{tabular}


Table 4 The correlation analysis results of serum IGF-1 and various factors

\begin{tabular}{|c|c|c|c|c|c|}
\hline & r & $P$ value & & r & $P$ value \\
\hline Age(year) & 0.042 & 0.481 & $\mathrm{BMI}\left(\mathrm{kg} / \mathrm{m}^{2}\right)$ & -0.116 & 0.051 \\
\hline $\mathrm{ALT}(\mathrm{U} / \mathrm{L})$ & -0.162 & 0.057 & $W C(c m)$ & -0.096 & 0.102 \\
\hline AST(U/L) & -0.138 & 0.089 & TT3(pmol/L) & -0.068 & 0.251 \\
\hline r-GT(U/L) & -0.148 & 0.109 & TT4(pmol/L) & -0.110 & 0.062 \\
\hline Uric(umol/L) & -0.113 & 0.055 & TSH(ulU/ml) & 0.096 & 0.104 \\
\hline $\mathrm{FBG}(\mathrm{mmol} / \mathrm{L})$ & -0.207 & 0.000 & TPOAb(IU/ml) & -0.056 & 0.345 \\
\hline $\mathrm{TC}(\mathrm{mmol} / \mathrm{L})$ & -0.056 & 0.345 & FINS(uU/ml) & -0.084 & 0.155 \\
\hline $\mathrm{TG}(\mathrm{mmol} / \mathrm{L})$ & -0.091 & 0.122 & 25(OH)D3(ng/L) & 0.123 & 0.037 \\
\hline $\mathrm{HDL}-\mathrm{C}(\mathrm{mmol} / \mathrm{L})$ & -0.140 & 0.057 & HOMA-IR & -0.023 & 0.079 \\
\hline LDL-C(mmol/L) & 0.000 & 0.998 & $\begin{array}{l}\text { Thyroid nodules } \\
\text { cross-sectional } \\
\text { area }\left(\mathrm{mm}^{2}\right)\end{array}$ & 0.086 & 0.145 \\
\hline
\end{tabular}

Q1 group $(\mathrm{OR}=0.560,95 \% \mathrm{CI}$ : 0.365-0.860); after further correction of serum IGF-1 by Model 3, the risk of thyroid nodules in Q3 group was still lower than that in Q1 group ( $\mathrm{OR}=0.562$, 95\% CI: 0.365-0.864). In Model 1 , as a reference for Q1 group, compared with Q4 group, the risk of thyroid nodules decreased $(\mathrm{OR}=0.628,95 \%$ CI: 0.501-0.788); after Model 2 corrected FBG, TC, TT3, TT4, and hypertension, the risk of thyroid nodules in Q4 group was still lower than that in Q1 group (OR = 0.644, 95\% CI: 0.478-0.866); after further correction of serum IGF-1 by Model 3, the risk of thyroid nodules in Q4 group was still lower than that in Q1 group $(\mathrm{OR}=$ 0.662, 95\% CI: 0.489-0.896).

\section{Correlation between IGF-1 level and the incidence of thyroid nodules}

According to the levels of IGF-1, all the subjects were divided into four groups, namely Q1: < 84.34 ng/L ( $n=$ 99), Q2: $84.35-120.01 \mathrm{ng} / \mathrm{L} \quad(n=100), \quad$ Q3: $120.02-$ $222.30 \mathrm{ng} / \mathrm{L}(n=100)$, and Q4: $\geq 222.31 \mathrm{ng} / \mathrm{L}(n=99)$. In Q1 group to Q4 group, the incidence of thyroid nodules was $79.8,85,73$, and $52.5 \%$, respectively. The results showed that compared with Q1 group, the incidence of thyroid nodules decreased in Q4 group, and a significant difference was observed as well (Table 6) $(P<0.001)$, while there was no significant difference between Q2 group and Q3 group compared with Q1 group (Fig. 2).

LRA showed that 25(OH)D3, TT3, FBG, TC, TT4, and hypertension were associated with thyroid nodules. The above-mentioned factors were also corrected, and the correlation between the level of IGF-1 and the incidence of thyroid nodules was further assessed. Compared with Model 1 as a reference for Q1 group, the risk of thyroid nodules in Q4 group decreased $(\mathrm{OR}=0.654,95 \% \mathrm{CI}$ : 0.530-0.807). In Model 1, as a reference for Q1 group, compared with Q4 group, the risk of thyroid nodules decreased (OR $=0.654,95 \% \mathrm{CI}$ : 0.530-0.807); after Model 2 corrected FBG, TC, TT3, TT4, and hypertension, the risk of thyroid nodules in the Q4 group was still lower than that in the Q1 group, however, the difference was not statistically significant.

\section{Discussion}

Vitamin D is a steroid hormone, and it not only can regulate the metabolism of calcium and phosphorus in

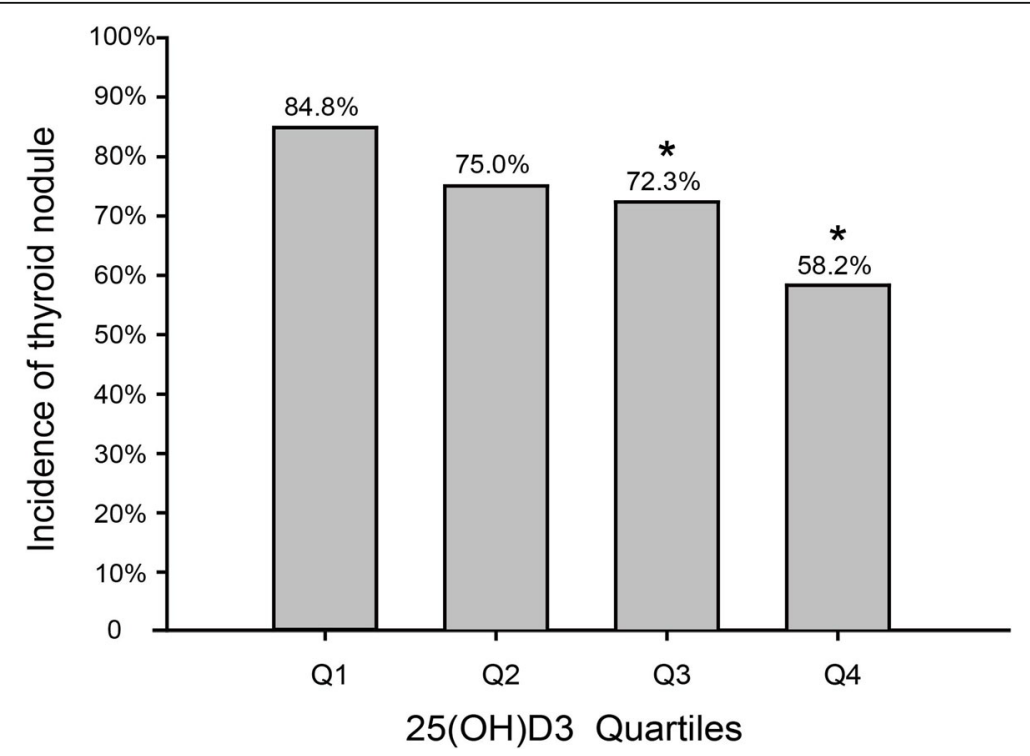

Fig. 1 The incidence of thyroid nodules in association with quartiles of serum 25(OH)D3 level. Note: Compared with subjects in the first quartile, a decrease of incidence of thyroid nodules was observed in the second, third, and the fourth quartiles $(P=0.083, P=0.030$, and $P<0.001)$. ${ }^{*} P<$ 0.05 , compared with subjects in the first quartile 
Table 5 The correlation between different 25(OH)D3 concentrations and thyroid nodules incidence

\begin{tabular}{lllll}
\hline & 25(OH)D3 quartiles & & & \\
\cline { 2 - 5 } & Q1: $\leq 5.19$ & Q2: 5.20-9.69 & Q3: 9.70-14.01 & Q4: $\geq 14.02$ \\
\hline No.cases/subjects & $84 / 99$ & $75 / 100$ & $73 / 101$ & $57 / 98$ \\
Model 1 & 1.00 (reference) & $0.536(0.263,1.092)$ & $0.628(0.501,0.788)$ & $0.682(0.481,0.969)$ \\
Model 2 & 1.00 (reference) & $0.493(0.208,1.169)$ & $0.560(0.365,0.860)$ & $0.644(0.478,0.866)$ \\
Model 3 & 1.00 (reference) & $0.510(0.208,1.249)$ & $0.562(0.365,0.864)$ & $0.622(0.489,0.896)$ \\
\hline
\end{tabular}

the body, but also plays an important role in the occurrence and development of numerous human diseases [4-6], therefore, a great number of individuals tend to consume vitamin $\mathrm{D}$ to prevent different diseases $[7,8]$. The content of serum $25(\mathrm{OH}) \mathrm{D} 3$ in the body is higher than that of serum $1,25(\mathrm{OH}) 2 \mathrm{D} 3$. Therefore, the serum level of 25(OH)D3 is typically selected to reflect the state of vitamin D in the body. IGF-1 is a peptide hormone composed of 70 amino acids and its amino acid chain is similar to that of the insulin chain [9]. After birth, the IGF-1 produced by the liver is the main source of circulating IGF-1, and the increase of circulating IGF-1 level is more tangible in puberty and adulthood [10]. Numerous studies have shown that the occurrence and development of cardiovascular diseases, malignant tumors, osteoporosis, and other diseases are associated with circulating IGF-1 levels $[11,12]$. This study aimes to clarify the changes and interactions of serum 25(OH)D3 and IGF-1 levels in thyroid nodules patients.

Vondra et al.'s study demonstrated that the increase in the risk of autoimmune thyroid disease was associated with deficiency of vitamin D. Serum 25(OH)D3 participates in the pathophysiological process of autoimmune thyroid diseases, and the risk of diffuse toxic goiter (Graves' disease) is associated with the gene encoding vitamin $\mathrm{D}$ binding protein and the polymorphism of $1,25(\mathrm{OH})$ 2D3 specific receptor remove "target cells" [13]. The relationship between vitamin D and thyroid disease is not still fully clear $[14,15]$. This study revealed that the serum $25(\mathrm{OH}) \mathrm{D} 3$ level in the nodular group was significantly lower than that in the control group. LRA showed that 25(OH)D3, IGF-1, FBG, TC, TT3, TT4, and high blood pressure were associated with thyroid nodules. Correlation analysis suggested that serum 25(OH)D3 was positively correlated with IGF-1.
Therefore, it is presumed that these factors may affect the relationship between serum 25(OH)D3 and the incidence of thyroid nodules. All the subjects were divided into four groups according to the four quantiles of serum 25(OH)D3. The incidence of thyroid nodules was significantly decreased in Q1 group to Q4 group. Compared with the Q1 group, the incidence of thyroid nodules in Q3 group and Q4 group reduced, and there were statistically significant differences $(P<0.05)$. After correcting the aforementioned factors, the risk of thyroid nodules still decreased with the increase of serum level of $25(\mathrm{OH}) \mathrm{D} 3$, that is, the incidence of thyroid nodules in the high-level of 25(OH)D3 was lower than the low-level of 25(OH)D3. Nathan et al.'s study revealed that deficiency of vitamin D was found in both thyroid cancer and thyroid nodules, however, there was no significant difference in the degree of deficiency of vitamin D between thyroid cancer and thyroid nodules [16]. However, a number of scholars believe that serum 25(OH)D3 level cannot be used as a monitoring index for nodular thyroid disease [17]. Although there are few reports concerning the relationship between vitamin $\mathrm{D}$ and thyroid nodules, previous studies have found that deficiency of vitamin $\mathrm{D}$ is a risk factor for thyroid disease, which is consistent with our results as well. Consequently, we speculated that vitamin $\mathrm{D}$ may be reduced in the production of thyroid nodules by inhibiting cell proliferation, and a large number of controlled studies should be conducted in the future.

A study on children with simple goiter showed that serum IGF-1 levels in children with goiter were lower than those children without goiter, reflecting that low-levels of IGF-1 in serum may be associated with thyroid enlargement [18]. The Völzke et al.'s study [19] disclosed that the occurrence of thyroid nodules was

Table 6 The correlation between different IGF-1 concentrations and thyroid nodules incidence

\begin{tabular}{lllll}
\hline & \multicolumn{1}{l}{ IGF-1 quartiles } & & & \\
\cline { 2 - 5 } & Q1: $\leq 84.34$ & Q2: 84.35-120.01 & Q3: 120.02-222.30 & Q4: $\geq 222.31$ \\
\hline No.cases/subjects & $79 / 99$ & $85 / 100$ & $73 / 100$ & $52 / 99$ \\
Model 1 & 1.00 (reference) & $1.435(0.687,2.995)$ & $0.827(0.595,1.151)$ & $0.654(0.530,0.807)$ \\
Model 2 & 1.00 (reference) & $1.193(0.468,3.042)$ & $0.709(0.461,1.092)$ & $0.783(0.607,1.010)$ \\
Model 3 & 1.00 (reference) & $1.274(0.491,3.3310)$ & $0.756(0.484,1.181)$ & $0.818(0.630,1.063)$ \\
\hline
\end{tabular}

Note: Model 1 is unadjusted. Model 2 is adjusted for FBG, TC, $\Pi 3, \Pi 4$, hypertension. Model 3 is further adjusted for 25(OH)D3 


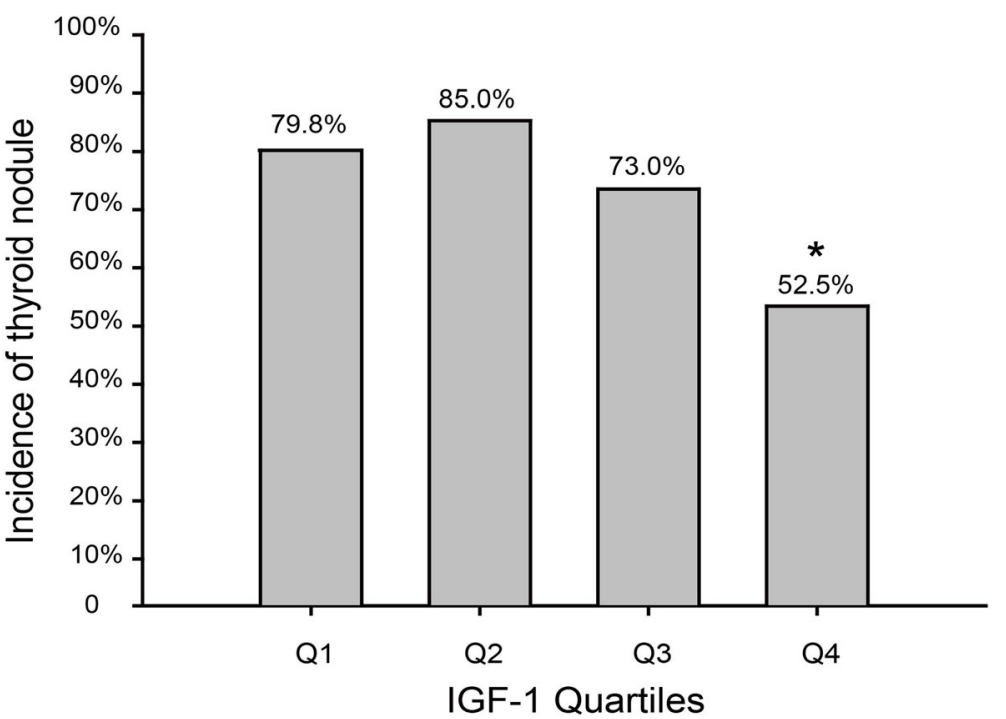

Fig. 2 The incidence of thyroid nodules in association with quartiles of serum IGF-1 level. Note: Compared with subjects in the first quartile, a decrease of incidence of thyroid nodules was observed in the second, third, and fourth quartiles $(P=0.335, P=0.259$, and $P<0.001)$. ${ }^{*} P<0.05$, compared with subjects in the first quartile

associated with the high level of IGF-1 in serum, however, that was only observed in male patients. The results of this study showed that the serum IGF-1 level in the nodular group was lower than that in the control group. Logistic regression analysis showed that 25(OH)D3, IGF-1, FBG, TC, TT3, TT4, and high blood pressure were associated with thyroid nodules as well. Correlation analysis suggested that serum IGF-1 was positively correlated with serum $25(\mathrm{OH}) \mathrm{D} 3$, and negatively correlated with fasting blood glucose. Therefore, it is speculated that these factors may affect the relationship between serum IGF-1 and the incidence of thyroid nodules. Similarly, all the subjects were divided into four groups according to the four digits of serum IGF-1, then the incidence of thyroid nodules was reduced in Q1 group to Q4 group. Compared with Q1 group, the incidence of thyroid nodules in Q4 group decreased, and there was statistically significant difference $(P<0.05)$. After the aforementioned factors were corrected, the occurrence risk of thyroid nodules was no longer decreased with the increase of serum IGF-1 level. An investigation showed that IGF-1 may play an important role in the pathogenesis of certain thyroid cold nodules [20]. Hsiao et al. [21] compared the serum IGF-1 of the thyroid cold and hot nodule group with the control group, and found that the concentration of serum IGF-1 in the hot nodule group or the cold nodule group was not significantly different from the control group $(P>$ 0.05). To date, the relationship between serum IGF-1 level and thyroid nodule is not still clear. In this study, the incidence of thyroid nodules was not decreased with the increase of serum IGF-1 levels after correction of those aforementioned factors. Therefore, we speculated that IGF-1 may be involved in the pathophysiological process of thyroid nodules along with 25(OH)D3 and FBG, however, further studies are required to confirm that finding.

There was no significant correlation between serum $25(\mathrm{OH}) \mathrm{D} 3$ or IGF-1 and the cross sectional area of thyroid nodules in this study, suggesting that serum $25(\mathrm{OH}) \mathrm{D} 3$ or IGF-1 may be independent of the size of thyroid nodules. LRA showed that serum $25(\mathrm{OH}) \mathrm{D} 3$ and IGF-1 were positively correlated with thyroid nodules. Correlation analysis showed that serum 25(OH)D3 was positively correlated with IGF-1. Therefore, we speculated that there may be some associations between serum 25(OH)D3 and IGF-1 in the formation of thyroid nodules. At present, there are relatively few reports concerning the relationship between serum 25(OH)D3, IGF-1, and thyroid nodules, however, similar reports have been found in some other diseases as well. A survey of type 2 diabetic patients showed that serum IGF-1 and other components were involved in the inflammatory process of diabetic nephropathy through vascular endothelial injury and inhibition of neovascularization. Serum 25(OH)D3 may be partially protected by inhibition of inflammation (e.g., inhibition of abnormal angiogenesis and vascular endothelial dysfunction [22]). Besides, a previous study conducted in Italy revealed that circulation of IGF-1 is a major vascular protection factor at low circulation levels of vitamin $\mathrm{D}$, and the mechanism is that IGF-1 strengthens the antioxidant and anti-apoptotic effects in endothelial cell culture [23]. Therefore, it can be concluded that the role of IGF-1 in 
disease is different. The results of this study suggest that serum $25(\mathrm{OH}) \mathrm{D} 3$ is a protective effect of thyroid nodules, and IGF-1 may affect the occurrence of thyroid nodules by $25(\mathrm{OH}) \mathrm{D} 3$, meanwhile serum IGF-1 may be as one of the indirect protective factors for thyroid nodules,which needs further study. There were also some limitations in the course of this study: 1) the study did not consider the age range of the subjects, 2) the pathological typing of thyroid nodules was not performed in this study, and 3) the ultrasound results were not recorded in detail and the relevant statistical analysis was not performed.

\section{Conclusions}

In summary. The incidence of thyroid nodules is relatively low in the high serum levels of $25(\mathrm{OH}) \mathrm{D} 3$, and serum $25(\mathrm{OH}) \mathrm{D} 3$ may be a direct protective factor for thyroid nodules. Serum IGF-1 may be as one of the indirect protective factors for thyroid nodules as well.

\section{Additional file}

Additional file 1: Questionnaire. (PDF $64 \mathrm{~kb}$ )

\section{Abbreviations}

25(OH)D3: Serum 25 hydroxyvitamin D3; ALT: Alanine aminotransfease; AST: Aspartate aminotransferase; BMI: Body mass index; FBG: Fasting blood glucose; FINS: Fasting insulin; HDL-C: High density lipoprotein cholesterol; HOMA-IR: Homeostasis model of assessment for insulin resistence index; IGF-1: Insulin-like growth factor-1; LDL-C: Low density lipoprotein cholesterol; LRA: Logistic regression analysis; r-GT: r-Glutamyl transferase; TC: Total cholesterol; TG: Triglyceride; TPOAb: Thyroid peroxidase antibody; TSH: Thyrotropin, thyroid stimulating hormone; TT3: Total triiodothyronine; TT4: Total thyroxine; WC: Waist circumference

\section{Acknowledgements}

Not applicable.

\section{Funding}

This study was supported by the Government-funded project for outstanding clinical talents of Hebei, China (361003) and the Mandatory plan for major research projects in medical science research of Hebei, China (20160077). The funder had no role on the study design, data analysis, interpretation and writing the manuscript in this study.

\section{Availability of data and materials}

The datasets generated and/or analyzed during the current study are not publicly available due to patient privacy but are available from the corresponding author on reasonable request.

\section{Authors' contributions}

XQD contributed to the study concept, design and drafting of the manuscript. $\mathrm{YL}$ and $\mathrm{CHZ}$ contributed to the collection and analysis of the data. JZF and XNW contributed to the supervision and interpretation of the data. LMW was the main investigator and was responsible for the overall study concept and design as well as the revision and final drafting of the manuscript. All authors read and approved the final manuscript.

\section{Ethics approval and consent to participate}

All work was conducted in accordance with the Declaration of Helsink (1964), the experimental protocol was approved by the Ethics Committee of Hebei General Hospital, and all the subjects signed the informed consent prior to beginning the study.
Consent for publication

Not applicable.

\section{Competing interests}

The authors declare that they have no competing interests.

\section{Publisher's Note}

Springer Nature remains neutral with regard to jurisdictional claims in published maps and institutional affiliations.

\section{Author details}

${ }^{1}$ Hebei Medical University, Shijiazhuang 050017, Hebei, China. ${ }^{2}$ Hebei North University, Zhangjiakou 075000, Hebei, China. ${ }^{3}$ Department of Pediatrics, Shijiazhuang Fourth Hospital, Shijiazhuang 050011, Hebei, China.

${ }^{4}$ Department of Endocrinology, Hebei General Hospital, Shijiazhuang 050051, Hebei, China.

Received: 7 December 2018 Accepted: 25 April 2019

Published online: 10 May 2019

\section{References}

1. Desser TS, Kamaya A. Ultrasound of thyroid nodules. Neuroimaging Clin N Am. 2008;18(3):463-78.

2. Roskies M, Dolev Y, Caglar D, et al. Vitamin D deficiency as a potentially modifiable risk factor for thyroid cancer. J Otolaryngol Head Neck Surg. 2012;41(3):160-3.

3. Liu YJ, Qiang W, Shi J, et al. Expression and significance of IGF-1 and IGF-1R in thyroid nodules. Endocrine. 2013;44(1):158-64.

4. Muschitz C, Kocijan R, Stütz V, et al. Vitamin D levels and comorbidities in ambulatory and hospitalized patients in Austria. Wien Klin Wochenschr. 2015;127(17-18):675-84.

5. Sadek KM, Shaheen H. Biochemical efficacy of vitamin D in ameliorating endocrine and metabolic disorders in diabetic rats. Pharm Biol. 2014;52(5): 591-6.

6. Oku $Y$, Tanabe $R$, Nakaoka $K$, et al. Influences of dietary vitamin $D$ restriction on bone strength, body composition and muscle in rats fed a high-fat diet: involvement of mRNA expression of MyoD in skeletal muscle. Journal of Nutritional Biochemistry. 2016;32:85-90.

7. Liao RX, Yu M, Jiang Y, et al. Management of osteoporosis with calcitriol in elderly Chinese patients: a systematic review. Clin Interv Aging. 2014;9(1): 515-26.

8. Rizzoli R, Stevenson JC, Bauer JM, et al. The role of dietary protein and vitamin $\mathrm{D}$ in maintaining musculoskeletal health in postmenopausal women: a consensus statement from the European Society for Clinical and Economic Aspects of osteoporosis and osteoarthritis (ESCEO). Maturitas. 2014;79(1):122-32.

9. Conti E, Musumeci MB, De GM, et al. IGF-1 and atherothrombosis: relevance to pathophysiology and therapy. Clin Sci. 2011;120(9):377-402.

10. Leifke E, Gorenoi V, Wichers $C$, et al. Age-related changes of serum sex hormones, insulin-like growth factor-1 and sex-hormone binding globulin levels in men: cross-sectional data from a healthy male cohort. Clin Endocrinol. 2010;53(6):689-95.

11. Djiogue $\mathrm{S}$, Nwabo Kamdje $\mathrm{AH}$, Vecchio L, et al. Insulin resistance and cancer: the role of insulin and IGFs. Endocr Relat Cancer. 2013;20(1):R1-R17.

12. Xian L, Wu X, Pang L, et al. Matrix IGF-1 maintains bone mass by activation of mTOR in mesenchymal stem cells. Nat Med. 2012;18(7):1095-101.

13. Vondra K. Vitamin D and Autoimmune thyroid diseases. Vnitrni Lekarstvi. 2016:62(Suppl 3):121.

14. Nettore IC, Albano L, Ungaro $P$, et al. Sunshine vitamin and thyroid. Rev Endocr Metab Disord. 2017:18(3):347-54.

15. Bizzaro $G$, Shoenfeld $Y$. Vitamin D and thyroid autoimmune diseases: the known and the obscure. Immunol Res. 2015;61(1-2):107-9.

16. Laney N, Meza J, Lyden E, et al. The prevalence of Vitamin D deficiency is similar between thyroid nodule and thyroid Cancer patients. Int J Endocrinol. 2010;(1):805716

17. Danilovic DL, Ferrazdesouza B, Fabri AW, et al. 25-Hydroxyvitamin D and TSH as risk factors or prognostic markers in thyroid carcinoma. PLoS One. 2016;11(10):e0164550.

18. Ersoy B, Gunes HS, Uyanik BS, et al. Interactions of thyroid hormones; insulin-like growth factor-1 (IGF-1), IGF binding proteins, and nutritional 
anthropometric parameters in school children with goiter detected by palpation. Exp Clin Endocrinol Diabetes. 2009;117(09):490-5.

19. Völzke H, Friedrich N, Schipf S, et al. Association between serum insulin-like growth factor-l levels and thyroid disorders in a population-based study. Journal of Clinical Endocrinology \& Metabolism. 2007;92(10):4039-45.

20. Liu YJ, Qiang W, Liu X J, et al. Association of insulin-like growth factor-1 with thyroid nodules[]]. Oncol Lett. 2011;2(6):1297-1301.

21. Hsiao PJ, Tsai JH. Increased insulin-like growth factor-1 receptors in thyroid tissues of Graves' disease. J Formos Med Assoc. 1994;93(11-12):925.

22. Shao Y, Lv C, Yuan Q, et al. Levels of serum 25(OH)VD3, HIF-1a, VEGF, vWf, and IGF-1 and their correlation in type 2 diabetes patients with different urine albumin creatinine ratio. Journal of Diabetes Research. 2016(12):892-5.

23. Ameri P, Canepa M, Fabbi P, et al. Vitamin D modulates the association of circulating insulin-like growth factor-1 with carotid artery intima-media thickness. Atherosclerosis. 2014;236(2):418-25.

Ready to submit your research? Choose BMC and benefit from:

- fast, convenient online submission

- thorough peer review by experienced researchers in your field

- rapid publication on acceptance

- support for research data, including large and complex data types

- gold Open Access which fosters wider collaboration and increased citations

- maximum visibility for your research: over $100 \mathrm{M}$ website views per year

At BMC, research is always in progress.

Learn more biomedcentral.com/submissions 